\title{
Selective Class I HDAC inhibitors Based on Aryl Ketone Zinc Binding Induce HIV-1 Protein for Clearance
}

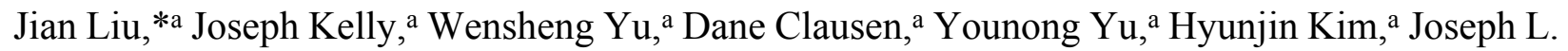
Duffy, ${ }^{a}$ Christine C. Chang, ${ }^{\text {a }}$ Robert W. Myers, ${ }^{a}$ Steve Caroll, ${ }^{b}$ Daniel J. Klein, ${ }^{\mathrm{b}}$ James Fells, ${ }^{\mathrm{b}}$ M. Katharine Holloway, ${ }^{\mathrm{b}}$ Jin Wu, ${ }^{\mathrm{a}}$ Guoxin Wu, ${ }^{\mathrm{b}}$ Bonnie J. Howell, ${ }^{\mathrm{b}}$ Richard J.O. Barnard, ${ }^{\mathrm{b}}$ Joseph A. Kozlowski ${ }^{\mathrm{a}}$

${ }^{a}$ Merck \& Co., Inc., 2000 Galloping Hill Road, Kenilworth, NJ 07033, USA

${ }^{\mathrm{b}}$ Merck \& Co., Inc., 770 Sumneytown Pike, West Point, PA 19486, USA

Normal phase column chromatography was carried out in the indicated solvent system (in the percentage of volume) using pre-packed silica gel cartridges for use on the Isco CombiFlashR or Biotage. LC-MS analysis was done using Agilent 1100 series LC-MSD VL on a YMC-Pack ODSAQ column ((120 A, 5 um particle size, $2.0 \mathrm{~mm}$ x $50 \mathrm{~mm})$. The flowing phase was $\mathrm{MeCN}$ and $\mathrm{H}_{2} \mathrm{O}$ which add $0.05 \%(\mathrm{v} / \mathrm{v})$ TFA. The flow rate was $2 \mathrm{~mL} / \mathrm{min}$. The effluent was monitored with a wavelength detector at 220. Nuclear Magnetic Resonance spectra were recorded on Varian spectrometers. Spectra were taken in the indicated solvent at ambient temperature, and the chemical shifts are reported in parts per million $(\operatorname{ppm}(\delta))$ relative to the lock of the solvent used. Resonance patterns are recorded with the following notations: br (broad), s (singlet), d (doublet), $\mathrm{t}$ (triplet), q (quartet), and $\mathrm{m}$ (multiplet).

Synthesis of HDACi 9 and 10

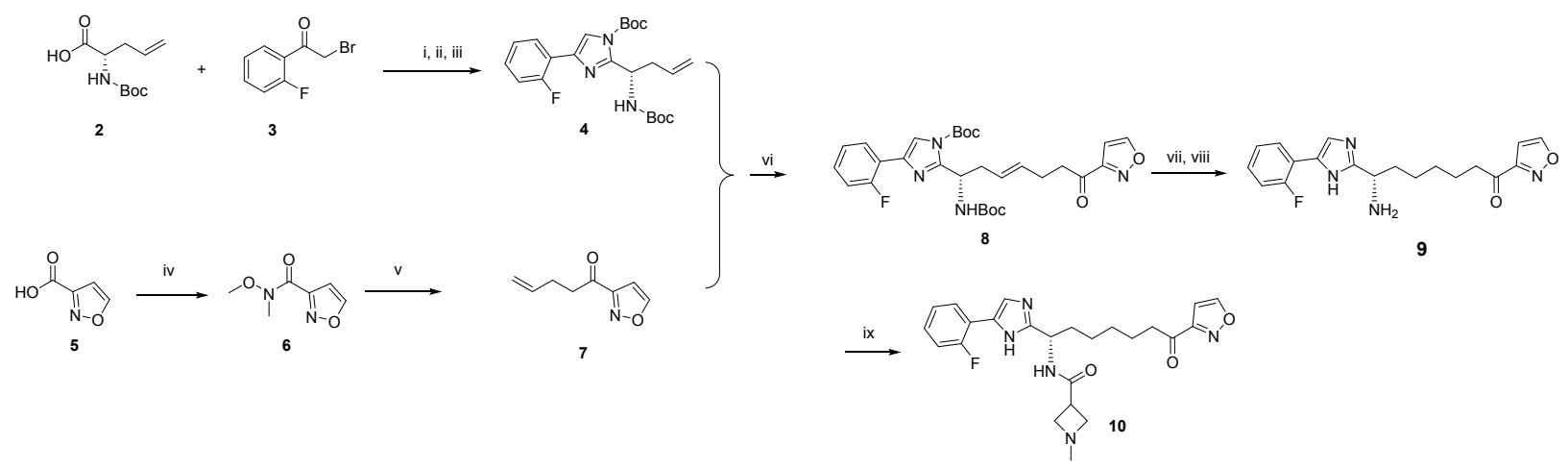

Intermediate 4

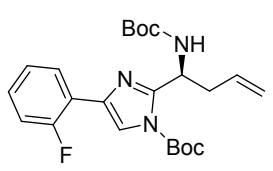

Step i: (S)-2-(2-fluorophenyl)-2-oxoethyl 2-((tert-butoxycarbonyl)amino)pent-4-enoate 
A $250 \mathrm{ml}$ one neck round bottom flask was charged with (S)-2-((tertbutoxycarbonyl)amino)pent-4-enoic acid (2, $1.60 \mathrm{~g}, 7.43 \mathrm{mmol})$ along with cesium carbonate (1.695 g, $5.20 \mathrm{mmol})$ and DMF (15 ml). The mixture was stirred and 2-bromo-1-(2fluorophenyl)ethanone $(3,1.694 \mathrm{~g}, 7.81 \mathrm{mmol})$ was added, and the resulting reaction mixture was stirred at room temperature for $2 \mathrm{hrs}$. The mixture was diluted with ethyl acetate $(40 \mathrm{~mL})$, the solid was filtered and washed with ethyl acetate $(3 \mathrm{x})$. The filtrate was then concentrated and the crude was purified by MPLC (40 g solica gel, 0 to $40 \%$ ethyl acetate in hexanes, $18 \mathrm{CV}$ ) to afford white solid product (S)-2-(2-fluorophenyl)-2-oxoethyl 2-((tertbutoxycarbonyl)amino)pent-4-enoate (2.60 g, $7.40 \mathrm{mmol}, 100 \%$ yield). LCMS (ESI) calc'd for $\mathrm{C}_{18} \mathrm{H}_{22} \mathrm{FNO}_{5}[\mathrm{M}+\mathrm{H}]^{+}:$352.1, found: 352.0.

Step ii: (S)-tert-butyl (1-(5-(2-fluorophenyl)-1H-imidazol-2-yl)but-3-en-1-yl)carbamate

A $100 \mathrm{ml}$ one neck round bottom flask was charged with (S)-2-(2-fluorophenyl)-2oxoethyl 2-((tert-butoxycarbonyl)amino)pent-4-enoate $(2.60 \mathrm{~g}, 7.40 \mathrm{mmol})$ along with ammonium acetate $(5.70 \mathrm{~g}, 74.0 \mathrm{mmol})$ in toluene $(20 \mathrm{ml})$. The mixture was then stirred and heated in an oil bath at $110^{\circ} \mathrm{C}$ for $3 \mathrm{hrs}$. After it was cooled to room temperature, the mixture was diluted with ethyl acetate $(100 \mathrm{~mL})$, washed with $\mathrm{NaHCO}_{3}$ (sat, $\left.30 \mathrm{~mL}\right)$, water, dried over $\mathrm{MgSO}_{4}$, filtered and concentrated to afford (S)-tert-butyl (1-(5-(2-fluorophenyl)-1H-imidazol-2yl)but-3-en-1-yl)carbamate which is used directly to next step without further purification. LCMS (ESI) calc'd for $\mathrm{C}_{18} \mathrm{H}_{22} \mathrm{FN}_{3} \mathrm{O}_{2}[\mathrm{M}+\mathrm{H}]^{+}$: 332.2, found: 332.0.

Step iii: (S)-tert-butyl 2-(1-((tert-butoxycarbonyl)amino)but-3-en-1-yl)-4-(2-fluorophenyl)-1Himidazole-1-carboxylate 4

A round bottom flask was charged with (S)-tert-butyl (1-(5-(2-fluorophenyl)-1Himidazol-2-yl)but-3-en-1-yl)carbamate (2.452 g, $7.40 \mathrm{mmol})$ along with DMAP (0.045 g, 0.370 $\mathrm{mmol})$ in $\mathrm{CH}_{2} \mathrm{Cl}_{2}(20 \mathrm{ml})$. The mixture was stirred while di-tert-butyl dicarbonate $(1.696 \mathrm{~g}, 7.77$ mmol) was added in one portion. The resulting reaction mixture was then stirred at room temperature for $3 \mathrm{hrs}$. The mixture was then concentrated and the crude was purified by MPLC (80 g silica gel, 0 to $30 \%$ ethyl acetate in hexanes, $18 \mathrm{CV}$ ) to afford the product (S)-tert-butyl 2(1-((tert-butoxycarbonyl)amino)but-3-en-1-yl)-4-(2-fluorophenyl)-1H-imidazole-1-carboxylate (2.94 g, $6.81 \mathrm{mmol}, 92 \%$ yield). LCMS (ESI) calc'd for $\mathrm{C}_{23} \mathrm{H}_{30} \mathrm{FN}_{3} \mathrm{O}_{4}[\mathrm{M}+\mathrm{H}]^{+}:$432.2, found: 432.0 .

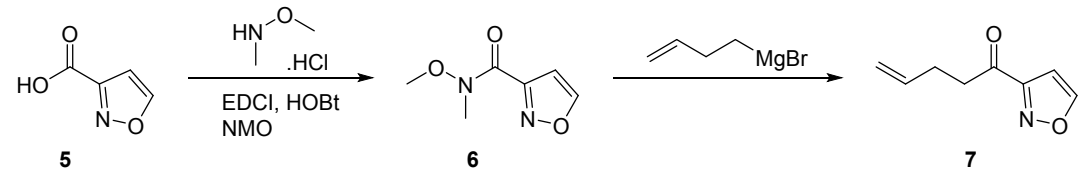

Step iv: Preparation of N-methoxy-N-methylisoxazole-3-carboxamide 6

HOBt (4.5 g, $29.4 \mathrm{mmol})$ and EDCI (5.4 g, $28.2 \mathrm{mmol})$ were added to solution of isoxazole-3-carboxylic acid (5, $3 \mathrm{~g}, 26.5 \mathrm{mmol})$ and N,O-dimethylhydroxylamine hydrochloride 
(2.7 g, $27.7 \mathrm{mmol})$ in DMF (5 ml) and DCM (7ml). 4-methylmorpholine (3 $\mathrm{ml}, 27.3 \mathrm{mmol})$ was added, then the mixture was stirred overnight. It was extracted with ether $(300 \mathrm{ml})$ and brine $(100 \mathrm{ml})$, the organic layer was separated, it was washed with brine, dried over $\mathrm{Na}_{2} \mathrm{SO}_{4}$, then filtered and the solvent was evaporated. The residue was purified by chromatography (Redisep $40 \mathrm{~g}$ column) eluting with 1/1 EtOAc/Hexanes yielding N-methoxy-N-methylisoxazole-3carboxamide (3g, $19.21 \mathrm{mmol}, 72.4 \%$ yield) as oil. LCMS (ESI) calc'd for $\mathrm{C}_{6} \mathrm{H}_{8} \mathrm{~N}_{2} \mathrm{O}_{3}[\mathrm{M}+\mathrm{H}]^{+}$: 157.1, found: 157.1. ${ }^{1} \mathrm{H}$ NMR $\left(400 \mathrm{MHz}, \mathrm{CDCl}_{3}\right) \delta 8.48(1 \mathrm{H}, \mathrm{d}, \mathrm{J}=1.6 \mathrm{~Hz}), 6.72(1 \mathrm{H}, \mathrm{s}), 3.80$ $(3 \mathrm{H}, \mathrm{s}), 3.40(3 \mathrm{H}, \mathrm{s}) \mathrm{ppm}$.

\section{Step v: Preparation of 1-(isoxazol-3-yl)pent-4-en-1-one 7}

But-3-en-1-ylmagnesium bromide ( $50 \mathrm{ml}, 25.00 \mathrm{mmol})$ was added to solution of $\mathrm{N}$ methoxy-N-methylisoxazole-3-carboxamide $(6,3 \mathrm{~g}, 19.21 \mathrm{mmol})$ in THF $(15 \mathrm{ml})$ at $\mathrm{rt}$, and it was stirred at $60^{\circ} \mathrm{C}$ for $3 \mathrm{~h}$. It was cooled to room temperature, sat. $\mathrm{NH}_{4} \mathrm{Cl}(2 \mathrm{ml})$ was added, then it was extracted with EtOAc $(250 \mathrm{ml})$ and water $(100 \mathrm{ml})$. The organic layer was separated, it was washed with brine, dried over $\mathrm{Na}_{2} \mathrm{SO}_{4}$, then filtered and the solvent was evaporated. The residue was purified by chromatography (Redisep $40 \mathrm{~g}$ column) eluting with $20 \%$ EtOAcHexanes yielding 1-(isoxazol-3-yl)pent-4-en-1-one 1-(isoxazol-3-yl)pent-4-en-1-one (2.3 g, $15.22 \mathrm{mmol}, 79 \%$ yield) as colorless oil. LCMS (ESI) calc'd for $\mathrm{C}_{8} \mathrm{H}_{9} \mathrm{NO}_{2}[\mathrm{M}+\mathrm{H}]^{+}:$: 152.1, found: $152.1 .{ }^{1} \mathrm{H} \mathrm{NMR}\left(500 \mathrm{MHz}, \mathrm{CDCl}_{3}\right) \delta 8.48(1 \mathrm{H}, \mathrm{d}, \mathrm{J}=1.6 \mathrm{~Hz}), 6.75(1 \mathrm{H}, \mathrm{d}, \mathrm{J}=1.6 \mathrm{~Hz})$, $5.86(1 \mathrm{H}, \mathrm{m}), 5.08(1 \mathrm{H}, \mathrm{dd}, \mathrm{J}=17.5, \mathrm{~Hz}), 5.01(1 \mathrm{H}, \mathrm{dd}, 17.5, \mathrm{~Hz}), 3.18(2 \mathrm{H}, \mathrm{t}, \mathrm{J}=7.5 \mathrm{~Hz}), 2.51$ $(2 \mathrm{H}, \mathrm{t}, \mathrm{J}=7.4 \mathrm{~Hz}) \mathrm{ppm}$.

Synthesis of HDACi 9

(S)-7-amino-7-(5-(2-fluorophenyl)-1H-imidazol-2-yl)-1-(isoxazol-3-yl)heptan-1-one
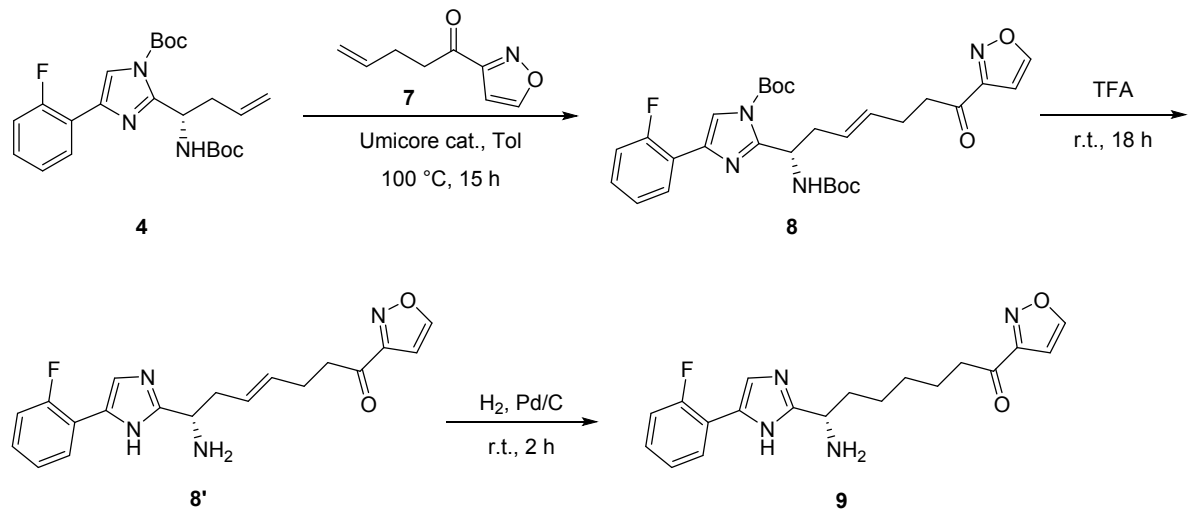

Step vi: tert-butyl (S,E)-2-(1-((tert-butoxycarbonyl)amino)-7-(isoxazol-3-yl)-7-oxohept-3-en-1yl)-5-(2-fluorophenyl)-1H-imidazole-1-carboxylate 8

A100 $\mathrm{ml}$ one neck round bottom flask was charged with toluene $(8 \mathrm{ml})$ and a mixture of (S)-tert-butyl 2-(1-((tert-butoxycarbonyl)amino)but-3-en-1-yl)-4-(2-fluorophenyl)-1H-imidazole1-carboxylate (4, $1.2 \mathrm{~g}, 2.78 \mathrm{mmol})$; 1-(isoxazol-3-yl)pent-4-en-1-one (7, 1.0 g, $6.62 \mathrm{mmol})$ and 
UMICORE M71 SIPR (100 mg, $0.122 \mathrm{mmol})$. The mixture was degassed and refilled with nitrogen, and then stirred at $55^{\circ} \mathrm{C}$ for three hours. After it was cooled to room temperature, the mixture was Purified on Analogix (Redisep 80g column) eluting with 30\% EtOAc-Hexanes yielding (S,E)-tert-butyl 2-(1-((tert-butoxycarbonyl)amino)-7-(isoxazol-3-yl)-7-oxohept-3-en-1yl)-4-(2-fluorophenyl)-1H-imidazole-1-carboxylate (37E) (1.6 g, $2.16 \mathrm{mmol}, 78 \%$ yield) as oil. LCMS (ESI) calc'd for $\mathrm{C}_{29} \mathrm{H}_{35} \mathrm{FN}_{4} \mathrm{O}_{6}[\mathrm{M}+\mathrm{H}]^{+}:$555.1, found: 555.1 .

Step vii: (S,E)-7-amino-7-(5-(2-fluorophenyl)-1H-imidazol-2-yl)-1-(isoxazol-3-yl)hept-4-en-1one

A $50 \mathrm{ml}$ one neck round bottom flask was charged with (S,E)-tert-butyl 2-(1-((tertbutoxycarbonyl)amino)-7-(isoxazol-3-yl)-7-oxohept-3-en-1-yl)-4-(2-fluorophenyl)-1Himidazole-1-carboxylate $(\mathbf{8}, 1.8 \mathrm{~g}, 2.60 \mathrm{mmol})$ in TFA ( $2 \mathrm{ml}) /$ DCM $(10 \mathrm{ml})$. The mixture was then stirred at room temperature for 1 hour. The reaction mixture was then concentrated, and the residue was dissolved in $\mathrm{CH}_{2} \mathrm{Cl}_{2}$ (20ml). The re-evaporation provided (S,E)-7-amino-7-(4-(2fluorophenyl)-1H-imidazol-2-yl)-1-(isoxazol-3-yl)hept-4-en-1-one TFA salt (1.6 g, $2.39 \mathrm{mmol}$, $92.0 \%$ yield) as a gum, TFA crude which was used directly to next step. LCMS (ESI) calc'd for $\mathrm{C}_{19} \mathrm{H}_{19} \mathrm{FN}_{4} \mathrm{O}_{2}[\mathrm{M}+\mathrm{H}]^{+}:$355.1, found: 355.0 .

Step viii: (S)-7-amino-7-(5-(2-fluorophenyl)-1H-imidazol-2-yl)-1-(isoxazol-3-yl)heptan-1-one 9

To a $50 \mathrm{ml}$ one neck round bottom flask was added $10 \% \mathrm{Pd} / \mathrm{C}, 50 \%$ in $\mathrm{H}_{2} \mathrm{O}(10 \mathrm{mg})$ to solution of (S,E)-7-amino-7-(4-(2-fluorophenyl)-1H-imidazol-2-yl)-1-(isoxazol-3-yl)hept-4-en1-one, TFA (8', $1.60 \mathrm{~g}, 2.31 \mathrm{mmol})$ in $\mathrm{MeOH}(25 \mathrm{ml})$. The system was connected to a hydrogen balloon through a three way joint. It was vacummed and refilled with hydrogen three times. The mixture was then stirred under hydrogen atomosphere for 3 hours. The mixture was filtered through celite, washed with methanol, and the filtrate was evaporated to provide residue yielding (S)-7-amino-7-(4-(2-fluorophenyl)-1H-imidazol-2-yl)-1-(isoxazol-3-yl)heptan-1-one, TFA salt $\left(9,1.6 \mathrm{~g}, 2.211 \mathrm{mmol}, 92 \%\right.$ yield) as oil. LCMS (ESI) calc'd for $\mathrm{C}_{19} \mathrm{H}_{21} \mathrm{FN}_{4} \mathrm{O}_{2}[\mathrm{M}+\mathrm{H}]^{+}$: 356.1, found: 357.0. . ${ }^{1} \mathrm{H} \mathrm{NMR}(400 \mathrm{MHz}, \mathrm{MeOD}) \delta 8.76(1 \mathrm{H}, \mathrm{s}), 7.99(1 \mathrm{H}, \mathrm{t}, \mathrm{J}=2 \mathrm{~Hz}), 7.60(1 \mathrm{H}, \mathrm{s})$, $7.34(1 \mathrm{H}, \mathrm{m}), 7.25(1 \mathrm{H}, \mathrm{d}, \mathrm{J}=8 \mathrm{~Hz}), 7.19(1 \mathrm{H}, \mathrm{m}), 6.76(1 \mathrm{H}, \mathrm{s}), 4.55(1 \mathrm{H}, \mathrm{t}, \mathrm{J}=2 \mathrm{~Hz}), 2.09(2 \mathrm{H}$, $\mathrm{m}), 1.74(2 \mathrm{H}, \mathrm{m}), 1.43(6 \mathrm{H}, \mathrm{m}) \mathrm{ppm}$.

Synthesis of HDACi 10:

Step ix: (S)-N-(1-(5-(2-fluorophenyl)-1H-imidazol-2-yl)-7-(isoxazol-3-yl)-7-oxoheptyl)-1methylazetidine-3-carboxamide $\mathbf{1 0}$

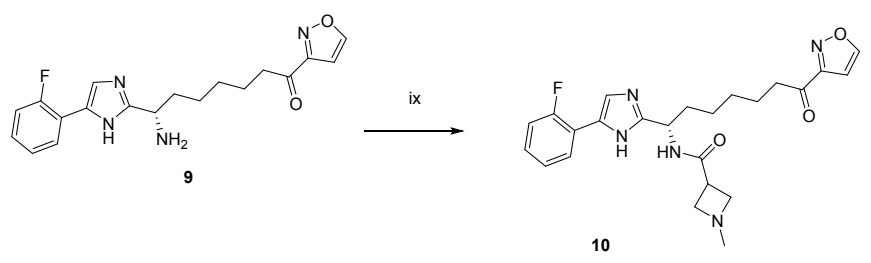


To a $25 \mathrm{ml}$ one neck round bottom flask a aloquot of methylmorpholine $(0.3 \mathrm{~mL}, 2.73 \mathrm{mmol})$ was added to a solution of (S)-7-amino-7-(4-(2-fluorophenyl)-1H-imidazol-2-yl)-1-(isoxazol-3yl)heptan-1-one (9, $100 \mathrm{mg}, 0.210 \mathrm{mmol})$ in methylene chloride $(1 \mathrm{~mL})$ and DMF $(1 \mathrm{~mL})$, followed by 1-methylazetidine-3-carboxylic acid (Synthonix) ( $70 \mathrm{mg}, 0.608 \mathrm{mmol}$ ), and COMU (CAS\#1075198-30-9, $150 \mathrm{mg}, 0.350 \mathrm{mmol}$ ). The resulting reaction mixture was stirred at room temperature overnight. The reaction mixture was then diluted with ethyl acetate $(100 \mathrm{~mL})$, washed with water, dried over $\mathrm{Mg}_{2} \mathrm{SO}_{4}$, filtered and concentrated. The crude was purified by MP HPLC (Redisep $40 \mathrm{~g}$ column) eluting with $10 \% \mathrm{MeOH} / \mathrm{CH}_{2} \mathrm{Cl}_{2} / \mathrm{NH}_{4} \mathrm{OH}$ yielding the product which was dissolved in acetonitrile/water and freeze dried/lyopholyzed yielding (S)-N-(1-(4-(2fluorophenyl)-1H-imidazol-2-yl)-7-(isoxazol-3-yl)-7-oxoheptyl)-1-methylazetidine-3carboxamide 10 (75 mg, $0.165 \mathrm{mmol}, 79 \%$ yield). LCMS (ESI) calc'd for $\mathrm{C}_{24} \mathrm{H}_{28} \mathrm{FN}_{5} \mathrm{O}_{3}[\mathrm{M}+\mathrm{H}]^{+}$: 454.2, found: 454.0. ${ }^{1} \mathrm{H}$ NMR $(400 \mathrm{MHz}, \mathrm{MeOD}) \delta 8.77(1 \mathrm{H}, \mathrm{s}), 7.92(1 \mathrm{H}, \mathrm{s}), 7.34(1 \mathrm{H}, \mathrm{s}), 7.29$ $(2 \mathrm{H}, \mathrm{m}), 7.13(1 \mathrm{H}, \mathrm{m}), 6.77(1 \mathrm{H}, \mathrm{s}), 5.04(1 \mathrm{H}, \mathrm{t}), 3.65(2 \mathrm{H}, \mathrm{m}), 3.42(2 \mathrm{H}, \mathrm{m}), 3.31(3 \mathrm{H}, \mathrm{s}), 3.05$ $(2 \mathrm{H}, \mathrm{m}), 1.95(2 \mathrm{H}, \mathrm{m}), 1.79(2 \mathrm{H}, \mathrm{m}), 1.2-1.5(8 \mathrm{H}, \mathrm{m}) \mathrm{ppm}$.

In the similar synthetic sequence, the following compounds were prepared:

Compound 11: (S)-N-(1-(4-(4-fluorophenyl)-1H-imidazol-2-yl)-7-(oxazol-2-yl)-7-oxoheptyl)-1methyl azetidine-3-carboxamide, LCMS (ESI) calc'd for $\mathrm{C}_{24} \mathrm{H}_{28} \mathrm{FN}_{5} \mathrm{O}_{3}[\mathrm{M}+\mathrm{H}]^{+}$: 454.2, found: 454.0. ${ }^{1} \mathrm{H}$ NMR $\left(500 \mathrm{MHz}, \mathrm{CD}_{3} \mathrm{OD}\right) \delta 8.11(1 \mathrm{H}, \mathrm{s}), 7.68(2 \mathrm{H}, \mathrm{t}, \mathrm{J}=7.0,2.2 \mathrm{~Hz}), 7.41(1 \mathrm{H}, \mathrm{s})$, $7.25(1 \mathrm{H}, \mathrm{s}), 7.09(2 \mathrm{H}, \mathrm{t}, \mathrm{J}=7.0 \mathrm{~Hz}), 5.02(1 \mathrm{H}, \mathrm{t}, \mathrm{J}=2.5 \mathrm{~Hz}), 3.58(2 \mathrm{H}, \mathrm{m}), 3.35(3 \mathrm{H}, \mathrm{s}), 3.30$ $(2 \mathrm{H}, \mathrm{m}), 3.02(1 \mathrm{H}, \mathrm{m}), 2.01(1 \mathrm{H}, \mathrm{m}), 1.88(1 \mathrm{H}, \mathrm{m}), 1.71(2 \mathrm{H}, \mathrm{m}), 1.28-1.44(6 \mathrm{H}, \mathrm{m}) \mathrm{ppm}$.

Compound 12: (S)-N-(1-(4-(4-fluorophenyl)-1H-imidazol-2-yl)-7-oxo-7-(thiazol-2-yl)heptyl)-1methylpiperidine-4-carboxamide, LCMS (ESI) calc'd for $\mathrm{C}_{26} \mathrm{H}_{32} \mathrm{FN}_{5} \mathrm{O}_{2} \mathrm{~S}[\mathrm{M}+\mathrm{H}]^{+}:$498.2, found: 498.2. ${ }^{1} \mathrm{H}$ NMR (400 MHz, MeOD) $\delta 8.02(1 \mathrm{H}, \mathrm{d}, \mathrm{J}=2.5 \mathrm{~Hz}), 7.94(1 \mathrm{H}, \mathrm{d}, \mathrm{J}=2.5 \mathrm{~Hz}), 7.68$ ( $2 \mathrm{H}, \mathrm{br}), 7.27(1 \mathrm{H}, \mathrm{s}), 7.09(2 \mathrm{H}, \mathrm{t}, \mathrm{J}=7.4,2.4 \mathrm{~Hz}), 5.01(1 \mathrm{H}, \mathrm{t}, \mathrm{J}=7.4 \mathrm{~Hz}), 3.31(3 \mathrm{H}, \mathrm{s}), 3.13$ $(2 \mathrm{H}, \mathrm{m}), 2.92(2 \mathrm{H}, \mathrm{br}), 2.25(1 \mathrm{H}, \mathrm{m}), 2.08(2 \mathrm{H}, \mathrm{m}), 1.98(1 \mathrm{H}, \mathrm{m}), 1.70-1.92(9 \mathrm{H}, \mathrm{m}), 1.24-1.48$ $(4 \mathrm{H}, \mathrm{m}) \mathrm{ppm}$.

Compound 13: (S)-N-(1-(4-(4-fluorophenyl)-1H-imidazol-2-yl)-7-(4-methyloxazol-2-yl)-7oxoheptyl)-1-methylpiperidine-4-carboxamide, LCMS (ESI) calc'd for $\mathrm{C}_{27} \mathrm{H}_{34} \mathrm{FN}_{5} \mathrm{O}_{3}[\mathrm{M}+\mathrm{H}]^{+}$: 496.3 found: 496.4. ${ }^{1} \mathrm{H}$ NMR (500 MHz, $\left.\mathrm{CD}_{3} \mathrm{OD}\right) \delta 7.80(1 \mathrm{H}, \mathrm{s}), 7.68(2 \mathrm{H}, \mathrm{br}), 7.27(1 \mathrm{H}, \mathrm{s})$, $7.09(2 \mathrm{H}, \mathrm{t}),, 7.09(2 \mathrm{H}, \mathrm{t}, \mathrm{J}=7.2,2.5 \mathrm{~Hz}), 5.01(1 \mathrm{H}, \mathrm{t}, \mathrm{J}=7.5 \mathrm{~Hz}), 3.31(3 \mathrm{H}, \mathrm{s}), 3.22(2 \mathrm{H}, \mathrm{m})$, $3.01(2 \mathrm{H}, \mathrm{m}), 2.42(1 \mathrm{H}, \mathrm{m}), 2.23(3 \mathrm{H}, \mathrm{s}), 1.80-2.01(6 \mathrm{H}, \mathrm{m}), 1.71(2 \mathrm{H}, \mathrm{m}), 1.25-1.44(2 \mathrm{H}, \mathrm{m})$ ppm.

Compound 14: (S)-N-(1-(4-(2-fluorophenyl)-1H-imidazol-2-yl)-7-(5-methylisoxazol-3-yl)-7oxoheptyl)-1-methylazetidine-3-carboxamide, LCMS (ESI) calc'd for $\mathrm{C}_{25} \mathrm{H}_{30} \mathrm{FN}_{5} \mathrm{O}_{3}[\mathrm{M}+\mathrm{H}]^{+}$: 468.2 found: $468.1 .{ }^{1} \mathrm{H}$ NMR $\left(500 \mathrm{MHz}, \mathrm{CD}_{3} \mathrm{OD}\right) \delta 7.77(2 \mathrm{H}, \mathrm{m}), 7.51(1 \mathrm{H}, \mathrm{m}), 7.36(2 \mathrm{H}, \mathrm{m})$, $6.41(1 \mathrm{H}, \mathrm{s}), 5.18(1 \mathrm{H}, \mathrm{br}), 3.31(3 \mathrm{H}, \mathrm{s}), 3.01(2 \mathrm{H}, \mathrm{m}), 2.93(2 \mathrm{H}, \mathrm{m}), 2.43(3 \mathrm{H}, \mathrm{s}), 2.04(2 \mathrm{H}, \mathrm{m})$, $1.74(2 \mathrm{H}, \mathrm{m}), 1.35-1.52(6 \mathrm{H}, \mathrm{m}) \mathrm{ppm}$. 
Compound 15: (S)-1-methyl-N-(7-oxo-1-(4-phenyl-1H-imidazol-2-yl)-7-(pyridin-2yl)heptyl)piperidine-4-carboxamide, LCMS (ESI) calc'd for $\mathrm{C}_{28} \mathrm{H}_{35} \mathrm{~N}_{5} \mathrm{O}_{2}[\mathrm{M}+\mathrm{H}]^{+}: 474.3$ found: 474.3. ${ }^{1} \mathrm{H}$ NMR $\left(400 \mathrm{MHz}, \mathrm{CD}_{3} \mathrm{OD}\right) \delta=11.29(\mathrm{~s}, 1 \mathrm{H}), 9.84(\mathrm{~d}, \mathrm{~J}=6.4 \mathrm{~Hz}, 1 \mathrm{H}), 8.61(\mathrm{~s}, 1 \mathrm{H}), 7.94$ $(\mathrm{d}, \mathrm{J}=7.6 \mathrm{~Hz}, 1 \mathrm{H}), 7.81(\mathrm{t}, \mathrm{J}=7.6 \mathrm{~Hz}, 1 \mathrm{H}), 7.61(\mathrm{~d}, \mathrm{~J}=7.2 \mathrm{~Hz}, 2 \mathrm{H}), 7.48-7.40(\mathrm{~m}, 1 \mathrm{H}), 7.39-7.24$ (m, 4H), 5.39 (d, J=7.6 Hz, 1H), 3.48 (t, J=12.0 Hz, 2H), 3.07 (t, J=6.8 Hz, 3H), 2.73 (s, 5H), $2.61(\mathrm{~s}, 1 \mathrm{H}), 2.20-1.78(\mathrm{~m}, 6 \mathrm{H}), 1.66-1.48(\mathrm{~m}, 2 \mathrm{H}), 1.39$ - $1.09(\mathrm{~m}, 4 \mathrm{H}) \mathrm{ppm}$.

Compound 16: (S)-7-amino-7-(5-(2-fluorophenyl)-1H-imidazol-2-yl)-1-(oxazol-4-yl)heptan-1one, LCMS (ESI) calc'd for $\mathrm{C}_{19} \mathrm{H}_{21} \mathrm{FN}_{4} \mathrm{O}_{2}[\mathrm{M}+\mathrm{H}]^{+}: 357.2$, found: $357.1, \mathrm{Rt}=0.832 \mathrm{~min} .{ }^{1} \mathrm{H}$ NMR $\left(400 \mathrm{MHz}, \mathrm{CD}_{3} \mathrm{OD}\right) \delta 8.58(\mathrm{~s}, 1 \mathrm{H}), 8.24(\mathrm{~s}, 1 \mathrm{H}), 8.00(\mathrm{brt}, \mathrm{J}=6.75 \mathrm{~Hz}, 1 \mathrm{H}), 7.50(\mathrm{~d}$, $\mathrm{J}=3.72 \mathrm{~Hz}, 1 \mathrm{H}), 7.11-7.28(\mathrm{~m}, 3 \mathrm{H}), 4.41-4.47(\mathrm{~m}, 1 \mathrm{H}), 2.88(\mathrm{t}, \mathrm{J}=7.14 \mathrm{~Hz}, 2 \mathrm{H}), 2.07-2.18(\mathrm{~m}$, $1 \mathrm{H}), 1.98-2.07$ (m, 1H), 1.65-1.74 (m, 2H), 1.31-1.46 (m, 4H), 1.26-1.31 (m, 2H) ppm.

Compound 17: (S)-7-amino-7-(4-(2-methoxyquinolin-3-yl)-1H-imidazol-2-yl)-1-(1H-pyrazol-3yl)heptan-1-one, LCMS (ESI) calc'd for $\mathrm{C}_{23} \mathrm{H}_{26} \mathrm{~N}_{6} \mathrm{O}_{2}[\mathrm{M}+\mathrm{H}]^{+}:$419.2, found: 419.1. ${ }^{1} \mathrm{H}$ NMR $\left(500 \mathrm{MHz}, \mathrm{CD}_{3} \mathrm{OD}\right) \delta 8.60(1 \mathrm{H}, \mathrm{s}), 7.82(2 \mathrm{H}, \mathrm{t}, \mathrm{J}=6.7 \mathrm{hz}), 7.64(2 \mathrm{H}, \mathrm{m}), 7.59(1 \mathrm{H}, \mathrm{t}, \mathrm{J}=7.0$ $\mathrm{Hz}), 7.41(1 \mathrm{H}, \mathrm{t}, \mathrm{J}=7.1 \mathrm{~Hz}), 6.78(1 \mathrm{H}, \mathrm{s}), 4.19(3 \mathrm{H}, \mathrm{s}), 4.05(1 \mathrm{H}, \mathrm{t} . \mathrm{m}), 2.95(2 \mathrm{H}, \mathrm{m}), 1.89(2 \mathrm{H}$, $\mathrm{m}), 1.72(2 \mathrm{H}, \mathrm{m}), 1.42(3 \mathrm{H}, \mathrm{m}), 1.30(1 \mathrm{H}, \mathrm{m}) \mathrm{ppm}$.

Compound 18: (S)-7-amino-1-(1H-imidazol-2-yl)-7-(4-(2-methoxyquinolin-3-yl)-1H-imidazol2-yl)heptan-1-one, LCMS (ESI) calc'd for $\mathrm{C}_{23} \mathrm{H}_{26} \mathrm{~N}_{6} \mathrm{O}_{2}[\mathrm{M}+\mathrm{H}]^{+}:$419.2, found: 419.1. ${ }^{1} \mathrm{H}$ NMR $\left(500 \mathrm{MHz}, \mathrm{CD}_{3} \mathrm{OD}\right) \delta 8.61(1 \mathrm{H}, \mathrm{s}), 7.81(3 \mathrm{H}, \mathrm{m}), 7.64(1 \mathrm{H}, \mathrm{s}), 7.59(1 \mathrm{H}, \mathrm{t}, \mathrm{J}=6.5 \mathrm{~Hz}), 7.40(1 \mathrm{H}$, $\mathrm{t}, \mathrm{J}=6.5 \mathrm{hz}), 7.21(1 \mathrm{H}, \mathrm{s}), 4.11(1 \mathrm{H}, \mathrm{m}), 2.96(2 \mathrm{H}, \mathrm{m}), 1.90(1 \mathrm{H}, \mathrm{m}), 1.73(1 \mathrm{H}, \mathrm{m}), 1.42(1 \mathrm{H}, \mathrm{m})$, $1.32(4 \mathrm{H}, \mathrm{m}), 0.89(3 \mathrm{H}, \mathrm{m}) \mathrm{ppm}$.

Compound 19: (S)-7-amino-7-(4-(2-methoxyquinolin-3-yl)-1H-imidazol-2-yl)-1-(5methylisoxazol-4-yl)heptan-1-one, LCMS (ESI) calc'd for $\mathrm{C}_{24} \mathrm{H}_{27} \mathrm{~N}_{5} \mathrm{O}_{3}[\mathrm{M}+\mathrm{H}]^{+}$: 434.2, found: 434.0. ${ }^{1} \mathrm{H}$ NMR $\left(500 \mathrm{MHz}, \mathrm{CD}_{3} \mathrm{OD}\right) \delta 8.75(1 \mathrm{H}, \mathrm{s}), 7.83(3 \mathrm{H}, \mathrm{m}), 7.64(1 \mathrm{H}, \mathrm{t}, \mathrm{J}=6.5 \mathrm{~Hz}), 7.44$ $(1 \mathrm{H}, \mathrm{t}, \mathrm{J}=6.5 \mathrm{~Hz}), 4.56(1 \mathrm{H}, \mathrm{br}), 4.21(3 \mathrm{H}, \mathrm{s}), 2.65(2 \mathrm{H}, \mathrm{m}), 2.30(3 \mathrm{H}, \mathrm{s}), 2.20(1 \mathrm{H}, \mathrm{m}), 2.12$ $(1 \mathrm{H}, \mathrm{m}), 1.71(2 \mathrm{H}, \mathrm{m}), 1.30-1.52(4 \mathrm{H}, \mathrm{m}) \mathrm{ppm}$.

Compound 20: (S)-7-amino-1-(5-(hydroxymethyl)oxazol-2-yl)-7-(4-(2-methoxyquinolin-3-yl)1H-imidazol-2-yl)heptan-1-one, LCMS (ESI) calc'd for $\mathrm{C}_{24} \mathrm{H}_{27} \mathrm{~N}_{5} \mathrm{O}_{4}[\mathrm{M}+\mathrm{H}]^{+}: 450.2$, found: 450.0. ${ }^{1} \mathrm{H}$ NMR (500 MHz, CD $\left.{ }_{3} \mathrm{OD}\right) \delta 8.75(1 \mathrm{H}, \mathrm{s}), 7.83(3 \mathrm{H}, \mathrm{m}), 7.63(1 \mathrm{H}, \mathrm{t}, \mathrm{J}=6.5 \mathrm{~Hz}), 7.43$ $(1 \mathrm{H}, \mathrm{t}, \mathrm{J}=6.4 \mathrm{~Hz}), 7.21(1 \mathrm{H}, \mathrm{s}), 4.61(2 \mathrm{H}, \mathrm{s}), 4.56(1 \mathrm{H}, \mathrm{t}, \mathrm{J}=5.0 \mathrm{~Hz}), 4.21(3 \mathrm{H}, \mathrm{s}), 3.03(2 \mathrm{H}, \mathrm{m})$, $2.20(1 \mathrm{H}, \mathrm{m}), 2.13(1 \mathrm{H}, \mathrm{m}), 1.74(2 \mathrm{H}, \mathrm{m}), 1.45(3 \mathrm{H}, \mathrm{m}), 1.36(1 \mathrm{H}, \mathrm{m}) \mathrm{ppm}$.

Compound 21: (S)-7-amino-7-(5-(2-fluorophenyl)isoxazol-3-yl)-1-(isoxazol-3-yl)heptan-1-one, LCMS (ESI) calc'd for $\mathrm{C}_{19} \mathrm{H}_{20} \mathrm{FN}_{3} \mathrm{O}_{3}[\mathrm{M}+\mathrm{H}]^{+}: 358.2$, found: 358.4. ${ }^{1} \mathrm{H} \mathrm{NMR}(400 \mathrm{MHz}$, DMSO-D6) $\delta 9.13(1 \mathrm{H}, \mathrm{s}), 8.69(2 \mathrm{H}, \mathrm{br}), 7.97(1 \mathrm{H}, \mathrm{t}, \mathrm{J}=6.4 \mathrm{~Hz}), 7.69(1 \mathrm{H}, \mathrm{m}), 7.50(1 \mathrm{H}, \mathrm{m})$, $7.46(1 \mathrm{H}, \mathrm{t}, \mathrm{J}=6.5), 7.10(1 \mathrm{H}, \mathrm{d}, \mathrm{J}=1.0 \mathrm{~Hz}), 6.86(1 \mathrm{H}, \mathrm{d}, \mathrm{J}=1.0 \mathrm{~Hz}), 4.60(1 \mathrm{H}, \mathrm{br}), 3.01(2 \mathrm{H}$, $\mathrm{m}), 1.89(2 \mathrm{H}, \mathrm{m}), 1.61(2 \mathrm{H}, \mathrm{m}), 1.3(4 \mathrm{H}, \mathrm{m}) \mathrm{ppm}$. 
Compound 22: (S)- 7-amino-7-(2-(4-fluorophenyl)-2H-1,2,3-triazol-4-yl)-1-(isoxazol-3-yl) heptan-1-one, LCMS (ESI) calc'd for $\mathrm{C}_{18} \mathrm{H}_{20} \mathrm{FN}_{5} \mathrm{O}_{2}[\mathrm{M}+\mathrm{H}]^{+}: 358.2$, found: $358.3 .{ }^{1} \mathrm{H}$ NMR (500 MHz, DMSO-D6) $\delta 9.12(1 \mathrm{H}, \mathrm{s}), 8.51$ (2H, br), $8.21(2 \mathrm{H}, \mathrm{s}), 8.04(2 \mathrm{H}, \mathrm{m}), 7.42$ (2H, M), 6.83 $(1 \mathrm{H}, \mathrm{s}), 4.59(1 \mathrm{H}, \mathrm{m}), 3.01(2 \mathrm{H}, \mathrm{t}, \mathrm{J}=7.0 \mathrm{~Hz}), 1.93(2 \mathrm{H}, \mathrm{m}), 1.66(2 \mathrm{H}, \mathrm{m}), 1.20-1.35(4 \mathrm{H}, \mathrm{m})$ ppm.

Compound 23: (S)-7-amino-7-(1-(4-fluorophenyl)-1H-pyrazol-3-yl)-1-(isoxazol-3-yl)heptan-1one, LCMS (ESI) calc'd for $\mathrm{C}_{18} \mathrm{H}_{20} \mathrm{FN}_{5} \mathrm{O}_{2}[\mathrm{M}+\mathrm{H}]^{+}: 357.2$, found: $357.3 .{ }^{1} \mathrm{H}$ NMR $(500 \mathrm{MHz}$, DMSO-D6) $\delta 8.78(1 \mathrm{H}, \mathrm{s}), 8.27(1 \mathrm{H}, \mathrm{s}), 7.81(2 \mathrm{H}, \mathrm{m}), 7.24(2 \mathrm{H}, \mathrm{t}, \mathrm{J}=7.2 \mathrm{hz}), 6.78(1 \mathrm{H}, \mathrm{s}), 6.59$ $(1 \mathrm{H}, \mathrm{s}), 4.48(1 \mathrm{H}, \mathrm{m}), 3.03(2 \mathrm{H}, \mathrm{t}, \mathrm{J}=5.0 \mathrm{~Hz}), 2.01(2 \mathrm{H}, \mathrm{m}), 1.75(2 \mathrm{H}, \mathrm{m}), 1.47(4 \mathrm{H}, \mathrm{m}) \mathrm{ppm}$.

Compound 24: (S)-7-amino-7-(1-(4-fluorophenyl)-1H-pyrazol-4-yl)-1-(isoxazol-3-yl)heptan-1one, LCMS (ESI) calc'd for $\mathrm{C}_{19} \mathrm{H}_{21} \mathrm{FN}_{4} \mathrm{O}_{2}[\mathrm{M}+\mathrm{H}]^{+}: 357.2$, found: $357.3 .{ }^{1} \mathrm{H} \mathrm{NMR}(500 \mathrm{MHz}$, DMSO-D6) $\delta 9.12(1 \mathrm{H}, \mathrm{s}), 8.60(1 \mathrm{H}, \mathrm{s}), 8.28(2 \mathrm{H}, \mathrm{br}), 7.90(1 \mathrm{H}, \mathrm{s}), 7.78(2 \mathrm{H}, \mathrm{m}), 7.32(2 \mathrm{H}, \mathrm{t}, \mathrm{J}$ $=6.5 \mathrm{~Hz}), 6.92(1 \mathrm{H}, \mathrm{s}), 4.25(1 \mathrm{H}, \mathrm{m}), 3.02(2 \mathrm{H}, \mathrm{t}, \mathrm{J}=5.5 \mathrm{~Hz}), 1.92(2 \mathrm{H}, \mathrm{m}), 1.61(2 \mathrm{H}, \mathrm{m}), 1.20-$ $1.30(4 \mathrm{H}, \mathrm{m}) \mathrm{ppm}$.

Compound 25: (S)-N-(1-(5-(2-fluorophenyl)oxazol-2-yl)-7-(isoxazol-3-yl)-7-oxoheptyl)-1methylazetidine-3-carboxamide, LCMS (ESI) calc'd for $\mathrm{C}_{24} \mathrm{H}_{27} \mathrm{FN}_{4} \mathrm{O}_{4}[\mathrm{M}+\mathrm{H}]^{+}: 455.2$, found:455.2, ${ }^{1} \mathrm{H}$ NMR (400 MHz, $\left.\mathrm{CD}_{3} \mathrm{OD}\right) \delta 8.76(\mathrm{~d}, \mathrm{~J}=1.76 \mathrm{~Hz}, 1 \mathrm{H}), 7.77$ (br dd, J=5.97, 7.53 $\mathrm{Hz}, 1 \mathrm{H}), 7.34-7.44(\mathrm{~m}, 2 \mathrm{H}), 7.19-7.32(\mathrm{~m}, 2 \mathrm{H}), 6.76$ (d, J=1.76 Hz, 1H), 5.17 (br s, 1H), 4.35$4.52(\mathrm{~m}, 2 \mathrm{H}), 4.04-4.21(\mathrm{~m}, 2 \mathrm{H}), 3.62$ (br s, 1H), 3.04 (br t, J=7.24 Hz, 2H), 2.92 (br s, 3H), 1.92-2.06 (m, 2H), 1.72 (br d, J=6.26 Hz, 2H), 1.44 (br s, 2H), 1.17-1.32 (m, 1H), 0.82-0.90 (m, 1H) ppm.

Compound 26: (S)-N-(1-(5-(2-fluorophenyl)-1,3,4-oxadiazol-2-yl)-7-(isoxazol-3-yl)-7oxoheptyl)-1-methylazetidine-3-carboxamide, LCMS (ESI) calc'd for $\mathrm{C}_{23} \mathrm{H}_{26} \mathrm{FN}_{5} \mathrm{O}_{4}[\mathrm{M}+\mathrm{H}]^{+}$: 456.2, found: 456.0. ${ }^{1} \mathrm{H}$ NMR (400 MHz, $\left.\mathrm{CD}_{3} \mathrm{OD}\right) \delta 8.70-8.81(\mathrm{~m}, 1 \mathrm{H}), 7.97-8.08(\mathrm{~m}, 1 \mathrm{H})$, 7.57-7.71 (m, 1H), 7.29-7.42 (m, 2H), 6.70-6.79 (m, 1H), 5.22-5.35 (m, 1H), 4.40-4.53 (m, 1H), 4.13-4.26 (m, 2H), 3.55-3.81 (m, 1H), 3.28-3.30 (m, 3H), 3.03-3.08 (m, 1H), 2.89-2.95 (m, 2H), $1.92-2.13(\mathrm{~m}, 2 \mathrm{H}), 1.66-1.80(\mathrm{~m}, 2 \mathrm{H}), 1.42-1.53(\mathrm{~m}, 4 \mathrm{H}) \mathrm{ppm}$.

\section{Biology Assay Protocols:}

\section{Human HDAC Enzyme Inhibitor Fluor-de-Lys Assay}

\section{Materials}

Recombinant human HDAC8 (BML-SE145-0100) enzymes, HDAC substrates BML-KI104 and BML-KI178, and HDAC developer solutions BML-KI105 and BML-KI176 were purchased from Enzo Life Sciences. Recombinant human HDAC5 and HDAC11 were purchased from BPS Bioscience (catalog numbers 50045 and 50021). Substrate Boc-Lys(TFA)-AMC was obtained from Bachem (catalog number I-1985). HDAC inhibitor suberoylanilide hydroxamic acid (SAHA) was obtained from Indofine and trichostatin A (TSA) was obtained from Sigma- 
Aldrich. D-myo inositol-1,4,5,6-tetraphosphate potassium salt $\left(\mathrm{IP}_{4}\right)$ was from Carbosynth (catalog MI 16761). HEPES pH 8.0 was from Boston BioProducts, Tween-20 from Fisher Scientific (BP337), TCEP was from Calbiochem and 7.5\% bovine serum albumin (BSA) from Life Technologies (15260037). 384-well, black assay plates were from Corning (3575). Recombinant human HDAC1, HDAC2, and HDAC3/SMRT heterodimer were prepared by the research laboratories of Merck \& Co., Inc., Kenilworth, NJ, USA. Full length human HDAC1FLAG was stably expressed in HEK-293F cells and purified using an anti-FLAG affinity chromatography with FLAG peptide $(100 \mu \mathrm{g} / \mathrm{ml})$ elution. The final concentration of HDAC1 was $1.98 \mathrm{uM}$ by Western Blot analysis and $1.39 \mathrm{uM}$ by active site titration. Full length human HDAC2-FLAG was expressed in baculovirus infected Sf9 cells and purified using an anti-FLAG affinity chromatography with FLAG peptide $(100 \mu \mathrm{g} / \mathrm{ml})$ elution. The eluted protein was then passed over an anti-HDAC1 immunoaffinity column to remove any complexes containing HDAC1. The final concentration of HDAC2 was $16.8 \mathrm{uM}$ by Western Blot analysis and $7.6 \mathrm{uM}$ by active site titration. Full length human HDAC3-FLAG was expressed in HEK-293F cells along with SMRT (amino acids 1-899)-6xHis; plasmid APP-0024) and purified using an antiFLAG affinity chromatography with FLAG peptide $(100 \mu \mathrm{g} / \mathrm{ml})$ elution. The eluted protein was then passed over an anti-HDAC1 immunoaffinity column to remove any complexes containing HDAC1. The final concentration of the HDAC3/SMRT complex was $2.03 \mathrm{uM}$ by Western Blot analysis and $1.37 \mathrm{uM}$ by active site titration.

\section{HDAC inhibition assays}

The histone deacetylase activities of HDAC1, HDAC2, HDAC3, HDAC5, HDAC6, HDAC8 and HDAC11 were measured in modified FLUOR DE LYS assays in 384-well format. In this assay, HDAC enzymes are initially incubated with an $\varepsilon$-acetyl (or -trifluoroacetyl)-L-lysine-containing substrate with a C-terminal amide having aminomethylcoumarin as the amine component. HDACs cleave the $\varepsilon$-acetyl group, rendering the resulting product susceptible to AMC cleavage by trypsin. The released AMC is then detected by its fluorescence.

The HDAC 1, 2, 5, 10 and 11 assays employed buffer A, which contained $20 \mathrm{mM}$ HEPES, $\mathrm{pH}$ $8.0,1 \mathrm{mM} \mathrm{MgCl}_{2}, 137 \mathrm{mM} \mathrm{NaCl}, 2.7 \mathrm{mM} \mathrm{KCl}, 0.05 \%$ BSA. The HDAC3/SMRT assay employed buffer B, consisting of $20 \mathrm{mM}$ HEPES, pH 8.0, $1 \mathrm{mM} \mathrm{MgCl}_{2}, 50 \mathrm{mM} \mathrm{NaCl}, 2.7 \mathrm{mM}$ $\mathrm{KCl}, 0.05 \% \mathrm{BSA}, 0.005 \%$ Tween 20 , and $10 \mu \mathrm{M} \mathrm{IP}$. The HDAC6 assay employed buffer $\mathrm{C}$, consisting of $20 \mathrm{mM}$ HEPES, $\mathrm{pH} 8.0,1 \mathrm{mM} \mathrm{MgCl} 2,137 \mathrm{mM} \mathrm{NaCl}, 2.7 \mathrm{mM} \mathrm{KCl}, 0.5 \mathrm{mM}$ TCEP (Calbiochem) and $0.05 \%$ BSA. The HDAC 8 assay employed buffer D, consisting of $20 \mathrm{mM}$ HEPES, pH 8.0, $1 \mathrm{mM} \mathrm{MgCl} 2,100 \mathrm{mM} \mathrm{NaCl}, 20 \mathrm{mM} \mathrm{KCl}, 0.1 \%$ n-octyl- $\beta$-D-glucoside (Anatrace) and $0.05 \% \mathrm{BSA}$. All steps were performed at room temperature $\left(23^{\circ} \mathrm{C}\right)$. The assay was performed by pre-incubating serial dilutions of test compounds with the target HDAC prior to initiation with substrate. Each compound was titrated in a 10-point dose response, using a 1:3 fold dilution scheme, with 0.15 ul of solution added by ECHO555 to the plate, followed by the addition of $20 \mu \mathrm{l}$ of the appropriate HDAC isoform diluted in appropriate assay buffer. The incubation was allowed to proceed for 3 hours, then the appropriate substrate diluted in assay buffer (final substrate concentration $\sim \mathrm{K}_{\mathrm{m}}$ ) was added and the reaction allowed to proceed for 60 
min. Final conditions used for each assay were: 1. HDAC 1, $0.3 \mathrm{nM}$ total enzyme, $20 \mu \mathrm{M}$ substrate BML-KI104; 2. HDAC 2, $1.5 \mathrm{nM}$ total enzyme, $40 \mu \mathrm{M}$ substrate BML-KI104; 3. HDAC 3/SMRT, $0.3 \mathrm{nM}$ total enzyme, $20 \mu \mathrm{M}$ substrate BML-KI104; 4. HDAC 5, $0.44 \mathrm{nM}$ total enzyme, $60 \mu \mathrm{M}$ substrate Boc-Lys(TFA)-AMC; 5. HDAC 6, $1.3 \mathrm{nM}$ total enzyme, $2.5 \mu \mathrm{M}$ substrate BML-KI104; 6. HDAC 8, $1.3 \mathrm{nM}$ total enzyme, $200 \square \mathrm{M}$ substrate BML-KI178; and 7. HDAC 11, $12 \mathrm{nM}$ total enzyme, $50 \mu \mathrm{M}$ substrate Boc-Lys(TFA)-AMC. The final high dose of test compound was $30 \mu \mathrm{M}(50 \mu \mathrm{M}$ for HDACs 5 and 11). For potent compounds, $900 \mathrm{nM}$ was used as the final high dose. The reactions were stopped and developed by addition of $30 \mathrm{ul}$ of HDAC developer solution containing a saturating level of HDAC inhibitor as follows: 1. HDACs 1, 2, 3 and 6, developer BML-KI105 (stock diluted 1:125, containing 20 uM SAHA, 2. HDAC 5, developer BML-KI176 (stock diluted 1:100, containing 20 uM TSA), 3. HDAC 8, developer BML-KI176 (1:100 plus 40 uM SAHA, and 4. HDAC 11, developer BML-KI176 (stock diluted 1:100, containing $20 \mathrm{uM} \mathrm{TSA}$ ). The plates are shaken to assure good mixing, briefly centrifuged, incubated for 30 minutes at room temperature and then the fluorescence intensity (excitation 380nm, emission 460nm) measured using a PHERAstar plate reader. For each assay plate, both minimal inhibition (100\% DMSO; 0\% inhibition) and maximal inhibition (either $10 \mathrm{uM} \mathrm{SAHA}$ or $100 \mathrm{uM} \mathrm{TSA} ; 100 \%$ inhibition) controls were added. For data analysis, background subtracted product (fluorescence) vs. time data for each inhibitor concentration was fitted using a 4parameter fit.

\section{Cellular Assays}

\section{Cell Maintenance}

Jurkat 2C4 cells were licensed from the laboratory of Dr. John Karn, Case Western Reserve University, School of Medicine. The details regarding this cell line are published (Pearson, R., Kin, Y.K., Hokello, J., Lassen, K., Friedman, J., Tyagi, M., Karn, J., 2008, J. Virol. 82:1229112303). The cells were grown in a T175 flask (Thermo Fisher, catalog number 159910) in RPMI 1640 containing L-glutamine and phenol red (Life Technologies, catalog number 11875-085), $5 \%$ heat inactivated fetal bovine serum (FBS; Life Technologies, catalog number 10100-147) and $100 \mu \mathrm{g} / \mathrm{ml}$ Penicillin-Streptomycin (Life Technologies, catalog number 15140-122) at $37^{\circ} \mathrm{C}$. An atmosphere of 5\% $\mathrm{CO}_{2}$ and $90 \%$ humidity was used for all culture work. Cells were split and reseeded into T175 flasks at a density of $0.2 \times 10^{6}$ cells $/ \mathrm{ml}$, in $40 \mathrm{ml}$ of media, every 3-4 days.

\section{$\underline{\text { Cell Assays }}$}

\section{Day 1:}

After the 3-4 day growth period, the cells are transferred from the T175 flask to a $50 \mathrm{ml}$ conical tube and gently pelleted at $1000 \mathrm{rpm}$ for 5 minutes. The supernatant was removed and the cells gently resuspended in assay media RPMI 1640 medium containing L-glutamine but without Phenol Red (Life Technologies, catalog number 11835-030), 5\% FBS and $100 \mu \mathrm{g} / \mathrm{ml}$ Penicillin- 
Streptomycin, and then reseeded such that the original flask is now divided into two T175 flasks. These flasks were returned to the incubator.

\section{Day 2:}

Cell Preparation: The next day, the cells are transferred from each T175 flask to an individual 50 $\mathrm{ml}$ conical tube and gently pelleted at $1000 \mathrm{rpm}$ for 5 minutes. The cells are gently resuspended in assay media $(30 \mathrm{ml})$ and pelleted again. The cell pellets are each resuspended in $30 \mathrm{ml}$ of RPMI 1640 medium containing L-glutamine but without Phenol Red, $100 \mu \mathrm{g} / \mathrm{ml}$ PenicillinStreptomycin and containing either $0.1 \%$ or $5 \%$ normal human serum (NHS; Biospecialty, catalog number 115-00 Anticoagulant free). The cells were counted using the ViCell (Beckman Coulter) and diluted as necessary. A Multidrop (Combi, Thermo Scientific) with a sterile head was used to seed the cells into the wells of a 384-well solid black plate with lid (Perkin Elmer, catalog number 6007660 ) at 4000 cells/30 $\mu \mathrm{l} /$ well for the 5\% NHS assay media and 6000 cells/30 $\square$ 1/well for $0.1 \%$ NHS assay. The plates are covered and returned to the incubator prior to compound addition.

Compound Preparation: Solutions of control inhibitor suberoylanilide hydroxamic acid (SAHA; Sigma, catalog number SML0061) and test compounds in 100\% DMSO were titrated into 384well polypropylene plates (Labcyte, catalog number P-05525) using a 20-point dose response and 2-fold dilutions. The reference compounds, DMSO and SAHA were then added to the compound plate. Using the Access system (Labcyte), $120 \mathrm{nl}$ of these inhibitor and control solutions were added to the individual wells of the plates containing the cells, and the plates were then returned to the incubator for $\sim 20 \mathrm{hr}$ (range from 18-24 hr). The final high concentration for SAHA and the test compounds in the assays was $40 \mu \mathrm{M}$. The final DMSO concentration in all wells was $0.4 \%$. The minimal induction reference compound used was DMSO and the maximal induction reference compound used was SAHA ( $2 \mu \mathrm{M}$ final concentration in the assay. No Jurkat $2 \mathrm{C} 4$ cell death was observed by the treatment of SAHA at $2 \mu \mathrm{M}$ over $\sim 20 \mathrm{hr}$ ).

\section{Day 3:}

The luciferase detection reagent was prepared by transferring the contents of one bottle of Steady-Glo buffer to one bottle of Steady-Glo aubstrate (Steady-Glo Luciferase Assay System, Promega, catalog number E2520), followed by gently mixing until the substrate is thoroughly dissolved and the solution is equilibrated to room temperature. The cell culture assay plates are removed from the incubator and brought to room temperature $(15 \mathrm{~min})$. The Steady-Glo Reagent is added to the plates $(30 \mu \mathrm{l} /$ well), which are then covered with a black lid and incubated for 10 minutes at room temperature. The plates are then read for luminescence on an Envision (Perkin Elmer) using the ultrasensitive mode (US LUM), 0.1 counts per second and 384-well aperture. Luminescence counts in the DMSO reference wells are considered as $0 \%$ induction, while those in the $2 \mu \mathrm{M}$ SAHA reference wells were considered as $100 \%$ induction. Dose response curves 
are plotted as test compound concentration (X-axis) vs. percent activation (Y-axis) using a 4parameter fit based on the Levenberg-Marquardt algorithm.

Table 1 HDAC inhibitors with aryl ketones as the zinc binding groups in vitro data with standard deviation for $\mathrm{n}$ tests.

\begin{tabular}{|c|c|c|c|c|c|c|}
\hline Comp \# & $\begin{array}{c}\text { HDAC1 } \\
\mathrm{IC}_{50}(\mathrm{nM}) \pm \mathrm{SD} \\
(\mathrm{n} \text { tests })\end{array}$ & $\begin{array}{c}\mathrm{HDAC} 2 \\
\mathrm{IC}_{50}(\mathrm{nM}) \pm \mathrm{SD} \\
(\mathrm{n} \text { tests })\end{array}$ & $\begin{array}{c}\mathrm{HDAC} 3 \\
\mathrm{IC}_{50}(\mathrm{nM}) \pm \mathrm{SD} \\
(\mathrm{n} \text { tests })\end{array}$ & $\begin{array}{l}\text { HDAC6 } \\
\mathrm{IC}_{50}(\mathrm{nM})\end{array}$ & $\begin{array}{c}\text { HDAC8 } \\
\mathrm{IC}_{50}(\mathrm{nM}) \pm \mathrm{SD} \\
(\mathrm{n} \text { tests })\end{array}$ & $\begin{array}{c}\text { Cell Assay (5\%NHS) } \\
\mathrm{EC}_{50}(\mathrm{nM}) \pm \mathrm{SD} \text { (n tests) } \\
(\% \text { Act } @ \max \text { dose })\end{array}$ \\
\hline 1 & $13 \pm 5.5(6)$ & $18 \pm 10(6)$ & $12 \pm 0.1(2)$ & $220 \pm 78(2)$ & $7100 \pm 910(3)$ & $198 \pm 22(8)$ \\
\hline 10 & $0.10 \pm 0.023$ & $0.47 \pm 0.06(5)$ & $0.087 \pm 0.006(5)$ & $>45000$ & $3.0 \pm 0.7(5)$ & $\begin{array}{c}4.7 \pm 0.4(6) \\
174 \% @ 2.5 \mu \mathrm{M}\end{array}$ \\
\hline 11 & $1.1 \pm 0.3(2)$ & $7.1 \pm 3(2)$ & $3.1 \pm 1.1(2)$ & $>45000$ & $100 \pm 30(2)$ & $\begin{array}{c}39 \pm 1.6(2) \\
138 \% @ 0.63 \mu \mathrm{M}\end{array}$ \\
\hline 12 & $5.8 \pm 2.0(2)$ & $24 \pm 4.3(2)$ & $2.0 \pm 0.6(2)$ & $>45000$ & $380 \pm 13(2)$ & $\begin{array}{l}2800 \pm 503(2) \\
152 \% @ 10 \mu \mathrm{M}\end{array}$ \\
\hline 13 & $8.3 \pm 1.1(2)$ & $50 \pm 12(2)$ & $50 \pm 14(2)$ & $>15000$ & $8000(1)$ & $\begin{array}{l}2300 \pm 220(2) \\
147 \% @ 5 \mu \mathrm{M}\end{array}$ \\
\hline 14 & $0.16 \pm 0.08$ & $0.76 \pm 0.33(2)$ & $0.07 \pm 0.02(2)$ & $>45000$ & $16 \pm 1.1(2)$ & $\begin{array}{c}20 \pm 1.7(2) \\
208 \% @ 78 \mathrm{nM}\end{array}$ \\
\hline 15 & $150 \pm 8(2)$ & $240 \pm 2(2)$ & NT & $>1000$ & NT & NT \\
\hline 9 & $1.4 \pm 0.2(4)$ & $8.5 \pm 1.4(4)$ & $1.2 \pm 0.4(4)$ & $>45000$ & $280 \pm 65(4)$ & $\begin{array}{c}178 \pm 73(4) \\
132 \% @ 1.25 \mu \mathrm{M}\end{array}$ \\
\hline 16 & $170 \pm 66(2)$ & $740 \pm 120(2)$ & $150 \pm 33(2)$ & $>45000$ & $>1000$ & $\begin{array}{c}>40000 \\
21 \% @ 20 \mu \mathrm{M} \\
\end{array}$ \\
\hline 17 & $250 \pm 110(2)$ & $700 \pm 320(2)$ & $230 \pm 56(2)$ & NT & NT & $\begin{array}{c}17000 \\
69 \% @ 40 \mu \mathrm{M} \\
\end{array}$ \\
\hline 18 & $1600(1)$ & $4900(1)$ & $1200(1)$ & NT & NT & NT \\
\hline 19 & $207 \pm 75(2)$ & $1300 \pm 230(2)$ & $90 \pm 13(2)$ & $>45000$ & $5000(1)$ & NT \\
\hline 20 & $194 \pm 22(2)$ & $470 \pm 101(2)$ & $120 \pm 44(2)$ & NT & NT & $\begin{array}{c}>20000 \\
107 \% @ 40 \mu \mathrm{M}\end{array}$ \\
\hline 21 & $3.1 \pm 0.3(2)$ & $21 \pm 4.6(2)$ & $3.2 \pm 0.7(2)$ & $>900$ & $603 \pm 303(2)$ & $\begin{array}{l}1700 \pm 320(2) \\
161 \% @ 5 \mu \mathrm{M}\end{array}$ \\
\hline 22 & $25 \pm 11(2)$ & $81 \pm 9(2)$ & $20 \pm 7(2)$ & $>45000$ & $445 \pm 56(2)$ & $\begin{array}{c}3600(1) \\
192 \% @ 10 \mu \mathrm{M} \\
\end{array}$ \\
\hline 23 & $21 \pm 9(2)$ & $86 \pm 10(2)$ & $15 \pm 4(2)$ & $>45000$ & $212 \pm 23(2)$ & $\begin{array}{c}1400 \pm 49(2) \\
191 \% @ 10 \mu \mathrm{M}\end{array}$ \\
\hline 24 & $16 \pm 3(2)$ & $61 \pm 11(2)$ & $13 \pm 4(2)$ & $>45000$ & $466 \pm 110(2)$ & $\begin{array}{c}4300 \pm 520(2) \\
192 @ 10 \mu \mathrm{M} \\
\end{array}$ \\
\hline 25 & $0.20 \pm 0.04(2)$ & $0.82 \pm 0.1(2)$ & $0.17 \pm 0.02(2)$ & $>900$ & $32 \pm 9(2)$ & $\begin{array}{c}14 \pm 0.1(2) \\
155 \% @ 39 \mathrm{nM} \\
\end{array}$ \\
\hline 26 & $51 \pm 11(2)$ & $101 \pm 15(2)$ & $23 \pm 4(2)$ & $>900$ & $>900$ & $\begin{array}{c}2100 \pm 860(2) \\
171 \% @ 10 \mu \mathrm{M}\end{array}$ \\
\hline
\end{tabular}

Compound 18 was tested only once due to filtering out by its low activity

\section{HDAC Enzyme Inhibitor GPCA Slow Binding Assay}

\section{Materials}

HDAC substrates BML-KI104 and developer BML-KI105 were purchased from Enzo Life Sciences and HDAC inhibitor suberoylanilide hydroxamic acid (SAHA) was obtained from Indofine. D-myo inositol-1,4,5,6-tetraphosphate potassium salt $\left(\mathrm{IP}_{4}\right)$ was from Carbosynth (catalog MI 16761). HEPES pH 8.0 was from Boston BioProducts, Tween-20 from Fisher Scientific (BP337) and 7.5\% bovine serum albumin (BSA) from Life Technologies (15260037). Polypropylene assay blocks (2 ml) were from Costar (3960) and 384-well, black assay plates were from Corning (3575). 
Recombinant human HDAC1, HDAC2, and HDAC3/SMRT heterodimer were prepared by the research laboratories of Merck \& Co., Inc., Kenilworth, NJ, USA. Full length human HDAC1FLAG was stably expressed in HEK-293F cells and purified using an anti-FLAG affinity chromatography with FLAG peptide $(100 \mu \mathrm{g} / \mathrm{ml})$ elution. The final concentration of HDAC1 was $1.98 \mathrm{uM}$ by Western Blot analysis and $1.39 \mathrm{uM}$ by active site titration. Full length human HDAC2-FLAG was expressed in baculovirus infected Sf9 cells and purified using an anti-FLAG affinity chromatography with FLAG peptide $(100 \mu \mathrm{g} / \mathrm{ml})$ elution. The eluted protein was then passed over an anti-HDAC1 immunoaffinity column to remove any complexes containing HDAC1. The final concentration of HDAC2 was $16.8 \mathrm{uM}$ by Western Blot analysis and $7.6 \mathrm{uM}$ by active site titration. Full length human HDAC3-FLAG was expressed in HEK-293F cells along with SMRT (amino acids 1-899)-6xHis; plasmid APP-0024) and purified using an antiFLAG affinity chromatography with FLAG peptide $(100 \mu \mathrm{g} / \mathrm{ml})$ elution. The eluted protein was then passed over an anti-HDAC1 immunoaffinity column to remove any complexes containing HDAC1. The final concentration of the HDAC3/SMRT complex was $2.03 \mathrm{uM}$ by Western Blot analysis and $1.37 \mathrm{uM}$ by active site titration.

\section{HDAC-HDAC inhibitor slow binding assay: Global Progress Curve Analysis (GPCA)}

The HDAC 1 and 2 assays employed buffer A, which contained $20 \mathrm{mM}$ HEPES, pH 8.0, $1 \mathrm{mM}$ $\mathrm{MgCl}_{2}, 137 \mathrm{mM} \mathrm{NaCl}, 2.7 \mathrm{mM} \mathrm{KCl}, 0.05 \% \mathrm{BSA}$. The HDAC3/SMRT assay employed buffer B, consisting of $20 \mathrm{mM}$ HEPES, pH 8.0, $1 \mathrm{mM} \mathrm{MgCl}_{2}, 50 \mathrm{mM} \mathrm{NaCl}, 2.7 \mathrm{mM} \mathrm{KCl}, 0.05 \% \mathrm{BSA}$, $0.005 \%$ Tween 20 , and $10 \mu \mathrm{M} \mathrm{IP}$. All steps were performed at room temperature $\left(23^{\circ} \mathrm{C}\right) . \mathrm{A}$ master mix was prepared in a 2-ml assay block for each inhibitor concentration (including a zero inhibitor control) by combining substrate BML-KI104 (332 $\mu \mathrm{l})$ and an HDAC inhibitor in 100\% DMSO (2.5 $\mu 1 ; 0.5 \%$ DMSO final) diluted in the appropriate buffer. In general, the inhibitor was dilution scheme employed 1:2 dilutions, with the highest final concentration at $\sim 10$-fold higher than the $\mathrm{IC}_{50}$. The reaction was initiated by the addition of the appropriately diluted HDAC isoform $(165 \mu \mathrm{l})$. The final concentrations of reagents for each assay were: $1.75 \mathrm{pM}$ active enzyme and $200 \mu \mathrm{M}$ substrate $\left(10 \mathrm{xK}_{\mathrm{m}}\right)$ for HDAC1, 2. $200 \mathrm{pM}$ active enzyme and $400 \mu \mathrm{M}$ substrate $\left(10 \mathrm{xK}_{\mathrm{m}}\right)$ for HDAC2 and $3.75 \mathrm{pM}$ active enzyme and $200 \mu \mathrm{M}$ substrate $\left(10 \mathrm{xK}_{\mathrm{m}}\right)$ for HDAC3/SMRT. The final inhibitor concentrations used are noted in the plots. For each experiment, the non-enzymatic background was defined by performing an assay in the presence of saturating $50 \mu \mathrm{M}$ final concentration of SAHA; this background remained relatively constant during the study. At each time point $(2,5,10,15,20,30,45,60,90,120,180,240,360$ min post-initiation), an aliquot of the Master Mix (30 $\mu \mathrm{l})$ was transferred into a well of a 384-well assay plate and $100 \mu \mathrm{M}$ SAHA in assay buffer $(10 \mu \mathrm{l})$ was added to stop the enzymatic reaction. At study termination (6-7 hours total incubation time), developer solution BML-KI-105 was added ( $20 \mu \mathrm{l}$; stock solution diluted 1:83, final stock dilution 1:250 in the assay) to each well, the plate was shaken to assure good mixing, briefly centrifuged, incubated for 30 minutes at room temperature and then the fluorescence intensity (excitation 380nm, emission 460nm) measured using a PHERAstar plate reader. For data analysis, background subtracted product fluorescence 
vs. time at each inhibitor concentration was fitted using the one step slow binding inhibition Global Progress Curve Analysis (GPCA) method as described (Zhang, R. and Windsor, W. T. "In vitro kinetic profiling of hepatitis $\mathrm{C}$ virus NS3 protease inhibitors by progress curve analysis." Methods Mol Bio. 2013 1030:59-79.)
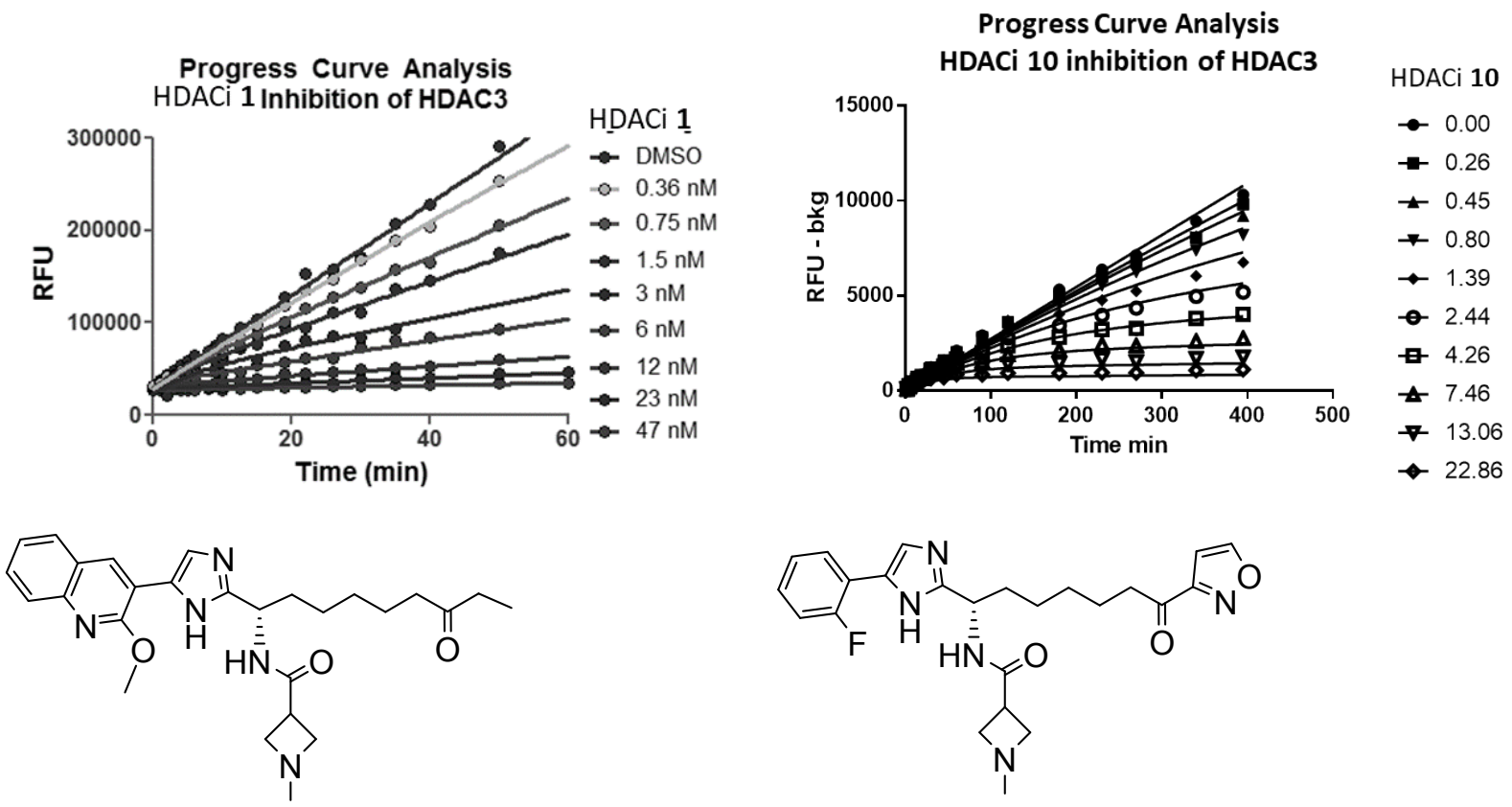

HDACi 1

HDACi 10

\begin{tabular}{|l|c|c|}
\hline & HDACi 1 & HDACi 10 \\
\hline Ki nM & 1.8 & 0.026 \\
\hline koff $\min -1$ & 0.18 & 0.000476 \\
\hline kon nM-1min-1 & $1.70 \mathrm{E}+06$ & $1.82 \mathrm{E}-02$ \\
\hline Half-Life min & 3.8 & 1458 \\
\hline $\begin{array}{l}\text { Residence time (1/koff) } \\
\text { min }\end{array}$ & 5.6 & 2103 \\
\hline
\end{tabular}

Human CD4+ T-cell separation from PBMC and treatment: CD4+ T-cells were isolated from PBMCs with EasySep ${ }^{\mathrm{TM}}$ Human CD4+ T-Cell Enrichment Kit in accordance with the manufacturer's instructions. In brief, 100 million cryopreserved PBMCs were thawed and washed once with $12 \mathrm{ml}$ cold complete RPMI medium. The cells were spun at $400 \mathrm{~g}$ for 8 minutes and the cell pellet was resuspended with $1 \mathrm{ml}$ complete RPMI medium. $15 \mathrm{ul}$ of biotin-antibody mixture from the CD4+ $\mathrm{T}$ cell negative selection kit was added into the tube and incubated at room temperature (RT) for 5 minutes, then $30 \mathrm{ul}$ of avidin magnetic beads was added into the tube, mixed and incubated at RT for another 5 minutes, tube was put into magnet for $2 \mathrm{~min}$, then transfer the unbound CD4+ T-cell suspension into a fresh tube, cell count and viability were determined in 
a Vi-cell instrument (Beckman Coulter, Brea, CA). Cells were then spun at $400 \mathrm{~g}$ for $5 \mathrm{~min}$ and the supernatant was aspirated, then the isolated CD4+ T cells were treated with the HDACi 10 or vorinostat, respectively for $72 \mathrm{~h}$ in the incubator at $37^{\circ} \mathrm{C}$ with $5 \% \mathrm{CO}$. Cells were collected and lysed at $2 \times 10^{\wedge} 6 / \mathrm{ml}$ with Simoa lysis buffer (1\% Triton X-100, 50\% Hi-FBS and 50\% Casein block in PBS) for 30 minutes with 1x protease inhibitor cocktail. The cell lysate was stored at $80^{\circ} \mathrm{C}$ for p24 measurement.

HIV gag p24 protein Simoa: HIV gag p24 protein was measured according to our previously published methods (Wu et al, 2017) in Quanterix HD-X. In brief, Samples stored at $-80{ }^{\circ} \mathrm{C}$ were thawed, cell lysates were centrifuged for 5 minutes at 10,000 $\mathrm{g}$ at room temperature to remove insoluble material prior to p24 measurement. All other assay reagents and assay reaction conditions were followed the manufacturer's p24 kit protocol from Quanterix. P24 assay kit was obtained from Quanterix and the p24 concentration was calculated from raw signal average enzyme per bead (AEB) by the HD-X software and the level was reported as $\mathrm{pg} / \mathrm{ml}$ or $\mathrm{pg} / \mathrm{million}$ cells in cell lysate for cell associated p24. p24 assay specificity was evaluated with BSA/PBS buffer instead of cell lysates in this study.

Data Analysis: In the p24 Simoa assay, standards and samples were run in duplicate. Graphs and figures were prepared with GraphPad Prizm software. Statistical significance in group comparisons is denoted conventionally by $* P<0.05$, $* * P<0.01$, and $* * * P<0.001$, using TukeyKramer honestly significant difference or Student's t-test. 